\title{
Experiences and Opinions of E-learners: What Works, What are the Challenges, and What Competencies Ensure Successful Online Learning
}

\author{
Michael F. Beaudoin \\ University of New England, \\ Maine, USA \\ MBeaudoin@une.edu
}

\author{
Gila Kurtz \\ The Center for Academic \\ Studies, Israel \\ gilaku@netvision.net.il
}

\author{
Sigal Eden \\ The Open University of Israel, Ra'anana, Israel \\ sigaled@openu.ac.il
}

\begin{abstract}
This paper reports findings of a survey of online learners from Western (mostly US), Israeli, Mexican, and Japanese cohorts. An instrument with 58 questions, including several open-ended items, allowing 318 respondents to tell their "stories" as online learners, was disseminated online in late 2008-early 2009. This research study attempts to better understand how students engage in online learning in terms of interacting with the medium and materials, with the instructor, and with one another. Also, with four distinct cohorts, representing four countries and cultures, there is some value in determining if there might be certain differences between these learner populations that are driven primarily by cultural orientation. The study revealed that the majority of respondents rated their satisfaction with their online learning to be positive. The findings further reveal that these cohorts produced a diverse list of positive/negative aspects influencing satisfaction/dissatisfaction, identified items critical to being a successful online learner, as well as challenges in their online learning environment. The majority indicated that success as online learners ultimately depended more on self-determination than on institutional support. Summary findings and analyses presented here provide evidence of some commonalities across groups and reveal experiences and opinions that can contribute to formulating a set of competencies useful to both online learners and providers.
\end{abstract}

Keywords: online learners, e-learning, comparative study, competencies

Material published as part of this publication, either on-line or in print, is copyrighted by the Informing Science Institute. Permission to make digital or paper copy of part or all of these works for personal or classroom use is granted without fee provided that the copies are not made or distributed for profit or commercial advantage AND that copies 1) bear this notice in full and 2) give the full citation on the first page. It is permissible to abstract these works so long as credit is given. To copy in all other cases or to republish or to post on a server or to redistribute to lists requires specific permission and payment of a fee. Contact Publisher@InformingScience.org to request redistribution permission.

\section{Introduction}

In 2007, the International Board of Standards for Training, Performance and Instruction (ibstpi) (http://ibstpi.org) undertook an ambitious new research project- to survey learners enrolled in diverse education and training offerings delivered in an online format. This data is intended to assist the research team in

An earlier, shorter version of this paper was presented at the Chais conference 2009, in Ra'anana, Israel, and included in Y. Eshet-Alkalai, A. Caspi, S. Eden, N. Geri, \& Y. Yair (Eds.), Proceedings of the Chais conference on instructional technologies research 2009: Learning in the technological era. Ra'anana: The Open University of Israel. http://www.openu.ac.il/research center eng/conferences.html 
ultimately developing a set of universally applicable competencies that learners consider critical to success in this environment and that could be widely disseminated for use, not only by online learners, but also by providers designing and delivering online education and training. Knowing what learners find to be the most effective and the least useful features and practices for success in online settings can be instructive to those wishing to enhance the teaching-learning process.

This paper reports findings of an online learner survey administered to Western (mostly US), Israeli, Mexican, and Japanese cohorts. The current study essentially attempts to better understand how students engage in online learning, in terms of interacting with the medium and with the environment in which they work, and apply new knowledge and skills acquired through their engagement with learning process. Another focus is on the interaction with the instructor, with one another, and with the learning materials. Also, with four distinct cohorts, representing four different countries and cultures, there is some value in determining if there might also be significant differences between these learner populations that are driven primarily by cultural orientation.

Online education literature is often characterized by its focus on "how to" teach online and how to optimally utilize the various features available in most instructional platforms, often based on authors' experiences teaching in this milieu. Less evident is if these recommended instructional techniques are based on data derived from systematic analysis of online student behaviors, attitudes, preferences, etc. As this online learner study attempts to arrive at a set of student skills or competencies that can enhance online learning experiences and outcomes, the review of literature focuses on sources that contribute to this effort.

Jones' study (2008) of distance education directors' main concerns revealed their preoccupation with the cost and support of technology, with less attention paid to quality or the level of satisfaction with instruction. While we fully recognize the criticality of technology as the medium by which online instruction is delivered and the milieu in which students process resources, we are alarmed by this continuing preoccupation with technology, seemingly at the expense of adequate attention paid to pedagogy. Accordingly, this study attempts to examine not simply respondents' reaction to the medium, as if they might be observers within it, but more so, to view them as participants in the dynamics that occur in that environment and how this impacts their learning, for better or worse, in online settings.

Assessments that incorporate stakeholders' perceptions of their learning environments (LEs) are consistent with predictors of student outcomes (Fraser, 1998). Variables within learning environments can be changed to achieve different affective and cognitive outcomes (Anderson \& Walberg, 1974). In many studies of environments and outcomes, dimensions of the former have been consistently identified as determinants of the latter (Fraser, 1998). Environments that students perceive as positive tend to lead to improved student achievement and attitudes (Chang \& Fisher, 2001). Research involving learning environments has a tradition of considering the association between perceptions of psycho-social characteristics of the environment and of students' cognitive and affective outcomes (For example, Kurtz, Amichai-Humburger, \& Kantor, 2009). Learning environments research has demonstrated that across languages, nations, cultures, subject matter, and educational levels, there are consistent associations between environmental perception and student outcomes (Fraser, 1998). Personal, institutional, and circumstantial variables are critical in affecting student success (Berge \& Huang, 2004).

Social structure has a strong influence on students' learning and satisfaction and on the method by which the course is presented (Swan, 2001). Students have need for social connection and a sense of presence in electronically mediated distance education (Paloff \& Pratt, 1999). In these settings, participants can become part of a social milieu with anyone with a computer. Klopfer's (1971) affective categories (e.g., students' attitudes toward subject matter, attitude toward inquiry, enjoyment of learning, interest in subject as a career) are among the variables to be identi- 
fied and measured to determine if and how certain learning environment characteristics have a positive association with student satisfaction and academic achievement.

Student engagement is defined in important ways by the environments and cultures in which it occurs. The convergence of parallel forces - rapid advancement of instructional technology, the collapse of barriers that has kept much of humanity separated, and the educational opportunities that are now available to anyone-anytime-anyplace - is changing higher education. Expanding instructional delivery to a diverse population is the new reality, and that population is the new majority of learners. As Inoue (2007) notes, this makes it difficult for students enrolled in online courses to visualize or relate to fellow classmates who now represent cultural differences in various geographical locations.

These advances in distributed learning technologies have made courses accessible to diverse learners worldwide, resulting not only in a diversity of cultures, but also in differences in learning styles. We must be alert to the fact that there are substantial differences in interaction and communication beyond the actual words being said or, in the case of online dialogue, the words being written or read (Janusxewsky \& Molenda 2008).

Does educational technology improve the performance of students, teachers, designers, and organizations? If so, what means are valid and reliable to verify that certain attributes of teachers and learners are those best suited to optimize performance? Palloff and Pratt (2001), as have others, define the attributes of successful online learners, listing characteristics that by now have become conventional wisdom in the field. Successful learners are seen as voluntarily seeking further education, having higher expectations, being more self-disciplined, older, enjoying learning for its own sake, demonstrating good thinking skills, able to work independently with limited structure, and recognizing the value of interacting with other online peers. Ashburn and Floden (2006) identify attributes of meaningful learning, building on the list developed by Jonassen, Peck, and Wilson (1999): intentionality, content centrality, authentic work, active inquiry, construction of mental models, and collaborative work.

The online learner is obviously a key component of the online learning environment, and determining his/her learner characteristics may not guarantee success, but it can help providers understand what factors and motivators can contribute to successful learning experiences in virtual settings. Dabbagh and Banna-Ritland (2005) report on the work of Dille and Mezack (1991), who studied the profile of distance learners, focusing on the locus of control. Students with an internal focus of control (those who attribute success and failure to personal behaviors and efforts) were more likely to succeed and persevere when faced with challenges. They also found that individual learning styles did not prove to be a significant predictor of success (presumably because distance education is inherently accommodating of various learning styles).

Anderson and Garrison (1998) indicate that the isolation that characterized an earlier era of distance education has been largely replaced by collaborative learning, suggesting that this trend demands emerging interactive skills of online learners, along with several attendant skills: social, discursive, group, and reflective skills. Similarly, the constructivist approach to learning, seemingly preferred by online teachers, also demands self-directed learning skills. Of course, the presence of these attributes in online learning environments presumes that those designing and delivering such courses possess the requisite competencies that lead to the implementation and application of those features in their courses.

Deriving a set of competencies useful to e-learning participants is the ultimate aim of this study. If, as some argue, the true purpose of e-learning is to support competence development rather than knowledge transfer, these "e-competencies" should ideally be applicable and beneficial to a wide spectrum of learners and be generally recognized and accepted as having reasonable reliability. Weinert (1999) offers a useful definition of competencies: A specialized system of abili- 
ties, proficiencies, or dispositions to learn or do something successfully, or to reach a specific goal, prerequisites for meaningful activities and which are influenced through experience and learning.

Respondents should be aware of the competencies they put in practice to learn online, even though only part of those competencies are likely to be manifested in the online classroom. Some competencies could go undetected by instructors in the virtual classroom but still be applied by the learner. This aspect of online learning invites a number of interesting possibilities for further inquiry, such as whether less experienced learners take part more or less actively than their more experienced counterparts, and if they use a greater or lesser repertoire of competencies. Also, are collaborative e-competencies more likely to occur or are more easily manifested than selfdirection competencies?

In recent research, Coates (2006) maintains that, despite the emergence of online education, there appears to be a reliance on serendipity to produce patterns of use for teaching and learning. And despite the proliferation of studies into online education in the past decade and widespread levels of adoption, most research has focused on financial, technical, and administrative aspects of these learning systems. In particular, Coates notes, there are very few published works on student engagement, and most of these are utilitarian, not conceptual. Further, student engagement studies are, in large part, based on assumptions about campus learning environments that ignore the implications of online learning and so present constraints in terms of advancing understanding of student engagement in these alternate settings. The current study is aimed to fill some of missing data by adding more dimensions of inquiry to this dynamic area of online education.

\section{Methodology}

A project team of ibstpi board members spent several months developing a survey with 58 questions, including several open-ended questions, allowing the respondents to tell their "stories" as online learners. A pilot test of the instrument was completed in fall 2007 to identify items needing possible revision, based on initial respondent feedback. The questionnaire, essentially what can be described as an audience analysis, attempted to gain extensive data regarding student characteristics behaviors and experiences, specifically in online settings. After some minor modifications, the final survey tool was disseminated online (in English), via Zoomerang in late 2007early 2008, yielding 86 respondents (all but 5 from the U.S), and these are referred to as Western. The questionnaire was also translated into Japanese and administered in early 2008, yielding 38 respondents. The survey tool was subsequently translated into Spanish and was administered to online learners in Mexico in March 2008, with a total of 150 completed surveys returned for analysis. Finally, the survey was translated in Hebrew; a pilot test was done in March 2008 and, after some minor modifications, was administered to online learners in Israel in April 2008, with 44 completed surveys returned. The total number of returned surveys from the four cohorts was 318.

Although minor variances exist between the four different language versions of the survey instrument, these do not change the primary line of inquiry intended for all respondent groups. In a very few instances, a question or two was omitted simply because it was not applicable to that cohort. Overall, any differences reflect nuances in language, mostly a consequence of English words not directly translatable in one or more of the other three languages used in the study.

Sampling was accomplished by specifying qualifying characteristics of eligible respondents to various providers of online offerings and requesting that they randomly select appropriate prospective respondents from various courses and/or programs they and/or their colleagues were associated with. Thus, respondents from each country included in the study reflect participation in varied online learning activities. The Mexican students were all enrolled via a single consortium 
(Consorcio Clavijero in Veracruz), though they represented learners located in various parts of that state.

To ensure that no particular field of study was represented by respondents, research team members and their colleagues assisting in the distribution of the questionnaire were advised to obtain responses from diverse programs. Thus, respondents spanned the gamut of online offerings, from credit to non-credit, short and long term courses, as well as enrollees in degree programs. Respondents were all adult learners, and all engaged in some form of formal education and training; persons involved in any type of informal learning activities (e.g., literary study groups, social networking sites, and the like) were excluded from this sample population.

Participation in this survey of online learners was entirely optional and anonymous. While it might be argued that less successful learners might be less inclined to participate in such a survey, results indicate that there is a wide variety of both positive and negative "stories" revealed among the 318 respondents. Presumably, a preponderance of highly favorable learning experiences in the data would imply over-representation by more successful learners, but there is no evidence that this occurred. Also, no effort was made to limit this study to experienced online learners who would represent mainly a successful learner population. Indeed, the researchers wished to include a continuum of learners that reflect the range of veteran and neophyte online students. The data indicates this was accomplished.

\section{Findings}

\section{Profile of Online Learners}

Seventy-one percent of Western respondents were female. The most dominant age group among these respondents was between 31-40 (39\%). Fifty-eight percent of the Japanese respondents were male. The most dominant age group among those respondents was between 31-40. Seventythree percent of the Israeli respondents were female. The most dominant age group among those respondents was between 21-30 (76\%).The gender split among the Mexican respondents was nearly equal: $48 \%$ female, $52 \%$ male. The most dominant age group among those respondents was between 21-30 (46\%) (See Table 1).

Table 1: Demographic characteristics of research groups

\begin{tabular}{|c|c|c|c|c|c|c|c|c|}
\hline \multirow[t]{2}{*}{ Characteristic } & \multicolumn{2}{|r|}{$\begin{array}{l}\text { Western } \\
\text { respondents }\end{array}$} & \multicolumn{2}{|r|}{$\begin{array}{l}\text { Japanese } \\
\text { respondents }\end{array}$} & \multicolumn{2}{|c|}{$\begin{array}{c}\text { Israeli } \\
\text { respondents }\end{array}$} & \multicolumn{2}{|c|}{$\begin{array}{l}\text { Mexican } \\
\text { respondents }\end{array}$} \\
\hline & $\mathrm{N}$ & $\%$ & $\mathrm{~N}$ & $\%$ & $\mathrm{~N}$ & $\%$ & $\mathrm{~N}$ & $\%$ \\
\hline Gender & & & & & & & & \\
\hline Female & 73 & 71 & 16 & 42 & 12 & 73 & 72 & 48 \\
\hline Male & 13 & 29 & 22 & 58 & 32 & 27 & 78 & 52 \\
\hline Total & 86 & 100 & 38 & 100 & 44 & 100 & $150 *$ & 100 \\
\hline Age & & & & & & & & \\
\hline Up to 20 & - & 16 & - & 16 & 2 & 5 & 7 & 5 \\
\hline $21-30$ & 14 & 39 & 6 & 37 & 32 & 76 & 68 & 46 \\
\hline $31-40$ & 34 & 28 & 14 & 29 & 7 & 17 & 52 & 35 \\
\hline $41-50$ & 24 & 17 & 11 & 18 & 1 & 2 & 16 & 11 \\
\hline+51 & 15 & 100 & 7 & 100 & - & - & 5 & 3 \\
\hline Total & 86 & & 38 & & 42 & 100 & 150 & 100 \\
\hline
\end{tabular}

* Although a total of 150 Mexicans responded to the survey and so are included in this demographic data summary, 45 were not aware that the survey involved more than one page and so most of the results reported reflect respondent data on 105 students, not 150. 


\section{Online Experiences Reported}

Each respondent was asked to share three experiences of online learning. The four respondent groups produced a total of 428 online learning experiences: Mexican students accounted for $35 \%$; and $24 \%$ were from the Israeli respondents; the remaining numbers were about equally divided among Western and Japanese students. Most of the online experiences occurred during the last 3 years (2005-2008), and were in higher education contexts

\section{Level of satisfaction with online experiences}

Respondents were asked to identify up to three online learning experiences and to indicate their level of satisfaction with each of these. Among Western students, 39\% rated one or more of those experiences as Very Good and $27 \%$ as Good, while $39 \%$ of Japanese students rated their experiences as Good, only 14\% as Very Good, and 36\% as Satisfactory. 11\% among each of these two cohorts considered one or more of their experiences as Poor. Yet, no Japanese respondents identified any experiences as Very Poor, though $4 \%$ of Western respondents did so. It might be noted here that some Japanese may be somewhat reluctant to commit to extremes in making such choices; thus, a possible explanation for relatively small numbers at either end of the continuum.

Forty-five percent of the Israeli responses rated one or more of those experiences as Good, 28\% as Very Good, and 19\% as Satisfactory. 8\% considered one or more of their experiences as Poor.

It appears that the Mexican students reported a higher satisfaction rate than other cohorts. Almost $90 \%$ considered their online experiences as Very Good or Good, while Israelis followed with $73 \%$ in the two highest categories, then Western (66\%), and lastly, Japanese (53\%). It may be that because the Mexican respondents are all enrolled via consortium that provides various student services to its constituents, higher satisfaction was reported.

\section{Elements of online experiences that influenced satisfaction}

A series of questions asked what were the elements of respondents' online experiences that most influenced their level of satisfaction, whether high or low. Among the Western respondents, there were a total of 222 elements listed, most of them on the positive side. Aspects relating to the course, mainly content and organization, led the list with $23 \%$. Next was the convenience and flexibility afforded by online learning $(21 \%)$, followed by online interaction $(18 \%)$, and the instructor's role, especially in providing feedback (16\%). Other elements garnering some attention were desirable features of the technology (10\%), and technical support (5\%). On the negative side were inadequate instructor performance $(8 \%)$, poor course content $(4 \%)$, problems with technology (3\%), negative experiences relating to interaction (3), and weak technical support (2\%).

Among Japanese students, the clearly dominant element was the course itself, with respect to both content and design: $29 \%$ identified this item as a positive influence, while half as many said this had a negative impact on their satisfaction. Second for this cohort was online discussion, noted by $25 \%$ as a positive factor and by only by 2 Japanese students as a negative influence. For Japanese respondents, instructor-related elements were next (22\%), followed by convenience (14\%), and time management $(13 \%)$, with only one negative associated with each of these elements.

Among the Israeli respondents, there were a total of 95 elements listed: 78 (82\%) positive and 17 negative $(18 \%)$. Aspects relating to the convenience and flexibility afforded by online learning, led the list with $38 \%$ of the positive responses. Next was the instructor's role, especially in providing feedback, (18\%) and online interaction (13\%), followed by the course, mainly content and organization (12\%), and technology (11\%). On the negative side, the following three aspects garnered approximately the same number of comments: poor course content $(35 \%$ of negative comments), problems with technology (35\%), and negative experiences relating to interaction $(30 \%)$. 
For the Mexican respondents, online participation (32\%) and professors (19\%) were cited as the key elements contributing to their satisfaction with their experiences. These dominant elements were followed by flexibility (10\%), assistance from the institution (9\%) and readings $(5 \%)$. Relatively few identified negative elements affecting their level of satisfaction.

The four cohorts produced a diverse list of positive/negative aspects, with no single element seeming to "take the lead" as the dominant element influencing satisfaction/dissatisfaction in their online learning. This finding suggests the complexity and the multi-dimensionality of the online learning environment.

\section{Items critical to being a successful online learner}

The questionnaire listed 10 items generally considered to be critical elements for successful online learning and then asked respondents to add two additional ones of their own.

Self motivation. Seventy-eight percent of the Western respondents and a remarkable $86 \%$ of the Japanese respondents ranked this item first, deeming it Very Critical, and another 14\% as Critical, making it the item seen as most essential for online learning success. Only 2\% considered this as Not at all Critical. For the Israeli students, this element ranked second (following Relationships with online facilitators) as the next most essential item for success. Of the entire respondent group, $62 \%$ ranked this item first, deeming it Very Critical and another $26 \%$ as Critical; $12 \%$ considered this as Somewhat Critical or Not at all Critical. Only $8 \%$ of Mexican students selected this as Important.

Typical comments were: "Success is completely dependent on myself;" "There's nobody but you;" "Without it you cannot succeed, no matter how good everything else... Outcome is in your own hands... It helps learner from start to finish."

Ability to manage own time. Closely following self-motivation, time management was rated as the next most essential item for success by Western and Japanese students. Indeed, the $93 \%$ who selected this option as Very Critical or Critical reflected only a single percentage point less than self-motivation. Only 7\% relegated this choice to Somewhat Critical or Not at all Critical. Of the entire Israeli respondent group, 55\% ranked this item first, deeming it Very Critical, and another $31 \%$ as Critical; $14 \%$ considered this as Somewhat Critical or Not at all Critical. Mexicans saw this as relatively unimportant, as only $8 \%$ responded that it was Important.

It is apparent from numerous comments that respondents saw this item as closely related to selfmotivation. Many remarks alluded to the need for setting study time aside each day or the need to create structure to meet deadlines, which, of course, requires a certain level of self-discipline. Others commented that this is a struggle for everyone, that deadlines are a big part of life and students need to learn how to do this, and that it is easy to let other demands have priority. One wrote that the freedom to do work when you want is the best part of online learning, but also its biggest challenge. Two comments succinctly expressed the general opinion that without this particular competency, "School just does not happen" and "It reflects your success."

Capacity to learn with limited support. This item, also related to self-direction, was chosen as Very Critical by $59 \%$ of all respondents; $62 \%$ of the Western respondents, and $50 \%$ of the Japanese respondents. The most frequent comment among Japanese students was, "You have to create your own environment to succeed," followed by, "You need to avoid giving up and to stay motivated." And several noted that "it is difficult to learn in an isolated environment." This item was chosen as Very Critical by $55 \%$ of all Israeli respondents and another $29 \%$ as Critical; $16 \%$ considered this as Somewhat Critical or Not at all Critical. Among Mexicans, 25\% chose this item as Important. 
Relationships with online facilitators. Among the Western respondents, $44 \%$ ranked this item as Very Critical and 34\% ranked it as Critical. But another 22\% said it was only Somewhat Critical or Not at all Critical. Many stated, using various phrases to express the feeling, that this was "Crucial to learning... Made me feel connected and valued...The most important feature...Makes it comparable to a face-to-face course." But, there were also other comments, such as "They assess your work...They are needed for feedback, guidance, problem solving, information regarding technology, clarification, and assessing work." Among the 44 Israeli respondents, $67 \%$ ranked this item as Very Critical and 29\% ranked it as Critical, making it the item seen as most essential for online learning success. Only two students (4\%) said it was only Somewhat Critical or Not at all Critical. $12 \%$ of Mexicans considered this Important.

These respondent comments seem to indicate that many online learners, while they indeed value online facilitators, they nonetheless see this role as exactly that (i.e., facilitators, rather than actual instructors). This would imply that many learners' experiences cause them to view those in such roles as important, but more so to be available for support as needed, rather than serving as instructors responsible for leading the learning process. Is this because so many of them have experienced "invisible" instructors and so have come to largely rely on their own resources to succeed in the online environment? Some comments would suggest this to be the case: "Mostly they just observe;" "I learn more from my peers;" "Much of the course is self-motivated." Among Japanese respondents, $31 \%$ stated they needed faculty support, primarily for feedback and answers to questions, to learn. Another $22 \%$ indicated the most valuable aspect of relationships with instructors is that it enhances motivation.

Enjoying the challenge of learning. This was the next most important factor (selected by $40 \%$ ) of Western and Japanese students, though it was deemed as noticeably more important by the Western respondents (44\%) than the Japanese students (31\%). Among Israeli students, this item was chosen as Very Critical by $24 \%$ of all respondents and another $31 \%$ as Critical; $45 \%$ considered this as Somewhat Critical, or Not at all Critical.

Fourteen percent of the Mexican students considered this Important. The most frequent comment from the Japanese was that this attitude was "needed to maintain motivation and to continue." Most of the comments by Western students echoed this sentiment, with many comments referring to this intrinsic aspect of the online experience being critical to motivation and success.

Confidence to be able to achieve learning goals. $41 \%$ of the Western respondents and $31 \%$ of the Japanese students saw this factor as Very Critical. This item was chosen as Very Critical by $26 \%$ of Israeli respondents and by another $48 \%$ as Critical; $26 \%$ considered this as Somewhat Critical or Not at all Critical. Ten of the 36 Japanese students stated confidence was critical for learning and/or motivation, and, interestingly, several observed that "confidence follows learning." Similarly, many Western students commented that confidence is essential, particularly in the online setting where support is not always easily available and so self-reliance and selfmotivation are needed. As one stated, "It is lonely at times, and one has to be one's own cheerleader." Another suggested that the lack of confidence "...is a reason why newcomers to online education drop out." Four Mexicans rated this as Important.

Ability to Express One's Ideas. This was rated by students at the same level of importance for success as the prior item (Confidence), selected by $38 \%$ of all respondents. Japanese and Western respondents rated this aspect in almost identical numbers as Very Critical or Critical $(86 \%$ and $85 \%$ respectively). This item was selected as Very Critical by $19 \%$ of Israeli respondents and another $24 \%$ as Critical; $57 \%$ considered this as Somewhat Critical or Not at all Critical. $22 \%$ of Mexicans saw this as Important.

Twenty-five percent of Japanese students expressed that this was essential for online discussion, and $22 \%$ said it was critical for written reports. Selected comments from the Western respon- 
dents capture the essence of why this item is seen as critical for successful online learning: "It's the only way we can communicate...It's all about writing if you want to relay your ideas in this format...It's the only way the instructor can evaluate your learning... Everything is done in writing and there are no other visual cues to express yourself." It is somewhat curious that this item rated relatively low among Israeli students, as they generally are seen as being quite assertive in academic settings.

Ability to Cope With non-Structured Settings. This element was seen by only $31 \%$ of all respondents as Very Critical, which might suggest that most respondents entered these courses with enough prior experience to deal with the environment or that they were able to adapt to it relatively easily without it compromising their learning. This is reinforced by the most common comments among Japanese students: "You must be used to non-structure to learn" (20\%), and "You must develop your own structure" (11\%). Among Israeli respondents, this element was seen by $36 \%$ of all respondents as Very Critical, and another $40 \%$ as Critical; $24 \%$ considered this as Somewhat Critical or Not at all Critical. This skill was the most popular choice among Mexican respondents, with $44 \%$ selecting it as Important.

It is of interest that while several of the Western learners commented that the limited structure in online environments is a challenge, $11 \%$ of the 85 respondents specifically stated that their online courses were, in fact, structured, or that they should be, no less so than courses in other formats. This pattern of responses suggests that at least some online learners balk at the conventional perception that a feature of such courses is that they are typically unstructured.

Relationships with Other Online Learners. Only $29 \%$ of the 125 respondents considered this to be Very Critical to online learning success. It is notable, however, that more than twice as many Japanese respondents saw it as Very Critical (46\%) than did Western respondents (22\%). 44\% consider this as only Somewhat Critical or Not Critical, but only $22 \%$ of Japanese students rated it in these two categories, while $53 \%$ of the other respondents felt similarly. This opinion of such relationships being relatively low in importance was evident also with Israeli students. Only 17\% of the 44 respondents considered this to be Very Critical to online learning success and another $31 \%$ as Critical. 55\% consider this as only Somewhat Critical or Not Critical. This was seen as the second most important feature for Mexican students, selected by $43 \%$.

Among the Western comments on this item were those to the effect that its value is "to know you aren't the only one." But even generally positive comments suggested this element was, to some extent, not especially highly valued, and that they could do nicely without it: "Collegiality is nice, but learning is specific to myself... If it's not face-to-face, its not really interaction...Interaction is important, but not relationships." This last remark might suggest that some respondents interpreted the use of the word "relationships" as more in the vein of establishing personal connections with peers, rather than seeing it is a mode of communication to enhance learning.

Three main themes emerged from the Japanese responses. 24\% saw this as important because it causes "motivation to rise" and 17\% said its value is to "expand one's views and ideas." Another $11 \%$ cited its appeal in "overcoming isolation," which appears often in one form or another as important to this population of learners.

Familiarity with Technology. Somewhat surprisingly, this aspect of online learning came in last among all respondents, with only $28 \%$ of Western and Japanese seeing it as Very Critical, while $29 \%$ of Israelis ranked this item first, another $45 \%$ as Critical, and $26 \%$ considered this as Somewhat Critical. No respondent marked the option as Not at all Critical. It was significantly less important to the Japanese students (only 6\% saw it as Very Critical, compared to $38 \%$ who did among the Western respondents). Eleven Mexicans saw this as Important. 
What might explain differences in these responses? Technical skills tend to be regarded as a prerequisite in Japan before entering into online courses. The primary comment among Japanese respondents was to the effect that "it's not a problem if you know computer skills in advance," suggesting that most of them came to online courses already possessing adequate technology skills to succeed. Yet, the impression given by many of the comments from Western students is that a fair amount of mastery of the technology is acquired while one is also mastering the course content. Even those respondents who indicated technology was not a problem for them also observed that other students in their courses seemed to struggle with this issue. Several also remarked that limited tech support requires self-sufficiency in dealing with computer problems.

\section{Dealing with Challenges in the Online Learning Environment}

Literally hundreds of challenges were identified in response to this question. Only 5 among the entire respondent population expressed that they encountered no challenges in their online learning experiences!

Time management issues emerged as far and away the most dominant issue for these learners, except for the Israelis. Most dealt with this key issue by simply organizing their time in whatever ways necessary so as not to compromise their learning, but this often resulted in personal deprivation in terms of sleep, health, family, and work. Quite a few time-related challenges were exacerbated by the lack of institutional support, thus requiring students to dedicate more time on whatever was challenging them to arrive at some sort of resolution.

Interestingly, $13 \%$ of Japanese students indicated they simply persevered as their main mode of dealing with problems. Technology-related issues were noted, and these too seem to have largely been addressed through individual solutions rather than institutional support. Japanese students may delay taking action, as they tend to think that time, patience, and optimism will solve the problem.

Most of the Israeli students interpreted this question as asking for their learning problems. Some of them cited the difficulty to learn on their own from a computer screen. Some felt the need to be active in discussion, posting comments to discussion just for the sake of being visible (and for grades).

\section{Suggestions to Improve Online Learning}

Respondents were invited to offer suggestions that would have improved their online learning in the experiences they cited previously. The four cohorts produced a total of 284 suggestions on diverse topics such as better learning environment, improve interaction/better feedback by instructors, improved technology, better course organization, clearer expectations, more technical training and support and adding live component. No single element seemed to emerge as the dominant suggestion, except the Mexican respondents who recommended improved interaction and better feedback from instructors. As with other results from this study, this finding suggests the complexity and the multi-dimensionality of the online learning environment.

\section{Summary of Findings}

What new insights can be derived from the results of this study of the experiences and opinions of more than 300 online learners in more than four countries to further inform our understanding of the dynamics of teaching and learning in this environment? Also, are these findings helpful in ultimately identifying online learner competencies critical for academic success and which, in turn, might aid providers to enhance their practice in the expanding distance education arena? And, can we discern any useful cross-cultural comparisons and contrasts in the responses of these 
four distinct cohorts? At this stage of analysis we are prepared to offer at least some preliminary conclusions. Selected highlights of findings are summarized below.

Online students' satisfaction. The study revealed that the majority of respondents rated their satisfaction with their online learning to be Very Good to Good. The range of responses reflected extremely high satisfaction among Mexicans (91\%), perhaps due to support received via their affiliation with the sponsoring consortium, to more modest satisfaction levels among Japanese (53\%), probably due, at least in part, to this society's aversion to expressing extreme opinions which may have tended to minimize their selection of responses at either end of the continuum.

What might be deduced from the finding that a strong majority of Mexican students (all enrolled via a consortium dedicating significant resources for student support services) reported highly positive experiences? At very least, this suggests that consortium-type arrangements among various online education providers may be a viable model for delivering such services. Pooling resources that offered in an efficient, consistent, and cost-effective manner might overcome feelings of isolation and self-dependency of many distant learners.

Elements influencing satisfaction. Among Westerners and Japanese, the course itself (in terms of organization and content) was the determining factor in influencing satisfaction. This was followed by the quality of instruction, interaction, convenience, and flexibility. For Mexicans, it was the instructor and the interaction, followed by flexibility and institutional support. Israelis cited convenience and flexibility as key elements. This suggests that, for those who are studying more or less independently, the quality of the course and the convenience of delivery are paramount in determining satisfaction. While for those enrolled through a specific institutional mechanism (e.g., a consortium), it is the services and support derived from that entity that is key to their ultimate satisfaction with the experience.

Challenges. Almost every respondent encountered one or more challenges in their online learning experiences, with time management the dominant challenge for all but Israeli students. Despite institutional efforts to enhance their student support services as enrollments in online courses increase, it seems that these issues are ultimately resolved by students utilizing their own resources, many by simply persevering.

Items critical for success. Excepting the Mexican respondents, the strongest determinant for success among these online learners was self-motivation, followed by time management, then capacity to learn with limited support. It is noteworthy that these choices relate to learner attributes, rather than to course attributes. This result would indicate that, for most of these students, success was primarily dependent on learner traits and behaviors, rather than any factors inherent to the course. This implies that key competencies for online learning success emanate from the learner, rather than from characteristics related to the learning environment. The least critical items were: ability to cope with unstructured settings, familiarity with technology, and (perhaps surprisingly, as it tends to counter the conventional wisdom) relationships with other online learners.

U.S. and Israeli respondents considered the role of instructors to be important to their success (78\% and 95\% respectively), but this was minimally important to Japanese and Mexican students. It seems that for some, those in this role are viewed largely as facilitators, rather than actually providing instruction. Many commented that faculty are most useful in offering support by answering questions, clarifying requirements, etc., rather than serving as the expert in the course content.

The fact that only a single respondent alluded to the role of online facilitator as that of managing discussion raises an important question here: Do the majority of online learners somehow devalue the instructional role in that setting compared to face-to-face faculty? And does the fact that "self-motivation" is considered the most critical item for online success while "relationships with 
instructors" ranked only 5th overall in importance among the choices represent somewhat of an indictment of faculty effectiveness in this milieu, or is it more an indication of students' selfsufficiency?

The Israeli respondents appear to be the most dependent cohort on interaction with their instructor for a successful learning process. The next three critical items, ranked as Very Critical by more than half of these respondents, represent a more intrinsic focus (e.g., based on the learner as independent learner: self motivation, ability to manage student's time, and capacity to learn with limited support). Far behind, the Israeli respondents ranked factors associated with technology, nonstructured settings, achieving leaning goal, enjoying the learning process, and expressing their ideas. Closing the list is interaction with other learners. While the literature emphasizes the importance of learner- learner interaction for meaningful and deep learning (Anderson, 2003), the Israeli respondents ranked this factor last in importance. A partial explanation can be based on the pedagogical model of their online experiences, which encourages individual learning

Though relationships with other learners was seen by Japanese and Mexican students to be more important than it was to Western and Israeli students, it garnered less than $50 \%$ of any cohort's rating as Very Critical or Critical, while the majority of all respondent groups saw it as relatively unimportant. In view of the significant interest in online interaction and the literature indicating its importance in this environment, some distance educators and scholars may be somewhat surprised at these numbers, which suggest these respondents do not consider this aspect of their experience essential to success. But, it also possible that some interpreted this question as referring more to personal relationships with peers, rather than online interactions.

Somewhat surprisingly, familiarity with technology came in last among all respondents, suggesting that many online learners come to this environment with the notion that technological proficiency is a "given." Several remarked that limited technical support requires self-sufficiency in dealing with computer problems.

Suggestions for improving online learning. Despite many suggested improvements, no single item emerged as dominant in this area. This implies that these learners did not encounter conditions in their respective learning environments so egregious as to elicit repeated recommendations for changes to enhance their learning

\section{Limitations}

Some limitations to this study are acknowledged here. The questionnaire, essentially what can be described as an audience analysis, attempted to gain extensive data regarding student characteristics, behaviors, and experiences. Despite its thoroughness, it did not ask respondents to indicate if their learning experiences resulted in completion or not. This would be useful to know, particularly in view of Herbert's finding (2006) that $25 \%$ of online students did not complete the online course in the semester in which they were enrolled. Nor did the study ask if the experience was their first, second, etc. And the survey did not ask students to identify their preferred learning style or to indicate if the online environment was compatible with that preferred style.

In retrospect, the research team also now recognizes that perhaps some repeat questions resulted, literally and figuratively, in diminishing returns, as some students did not choose to add any new responses to these repeat questions, which also may have made the survey a bit longer than necessary. Also, the first administration of the survey should have been limited to respondents in the US, to more closely match the other cohorts, which represent specific countries. The initial group included only a small number of students (less than 10\%) living and studying in some half dozen other countries. Encompassing a wider sample of online learners representing other regions (e.g., Europe) was a desired goal, but not feasible once it was realized how much additional time was required to accommodate just two additional cohorts from Mexico and Israel. 
While the research team would have ideally preferred to limit the study to only those learners with experience in three or more online courses, on the assumption that they would have greater insight into the dynamics of the online environment by virtue of exposure to more than just one activity, to qualify the respondents in this manner would be difficult and might also significantly reduce the number of responses. Thus, some respondents' answers may reflect only a single, short-term online experience.

Another limitation is the relatively small research sample. Though we cannot generalize these results to the overall population of online learners, or even to learners from the countries represented in this study, the research does reveal patterns of responses that, with further validation, provide increased understanding and useful insights into what most impacts learners' success in online settings and, hopefully, will prompt additional analyses of these phenomena.

\section{Further Research and Practical Applications}

What about further inquiry related to this study? Deriving a set of competencies useful to elearning participants is the ultimate aim of this study. Weinert (2001) offers a useful definition of competencies: A specialized system of abilities, proficiencies, or dispositions to learn or do something successfully, or to reach a specific goal, prerequisites for meaningful activities and which are influenced through experience and learning. If, as some argue, the true purpose of elearning is to support competence development rather than knowledge transfer, these "ecompetencies" should be generally recognized and accepted as having reasonable reliability and benefits for use by a wide spectrum of both learners and teachers.

It is hoped, then, that this research provides some useful information on the experiences and opinions of representative online learners in a variety of cultural settings, through a better understanding of the teaching-learning phenomena that occur in online environments. This insight will culminate in a set of valid and reliable competencies currently under development by the International Board for Standards, Training, Performance, and Instruction that should ultimately inform, influence, and improve our practice. Meanwhile, we invite the readers to also share their own reactions and ideas to augment this research.

\section{References}

Anderson, T. (2003). Getting the mix right again: An updated and theoretical rationale for interaction. The International Review of Research in Open and Distance Learning, 4(2). Retrieved from: http://www.irrodl.org/index.php/irrodl/article/view/149/230

Anderson, T., \& Garrison, D. R. (1998). Learning in a networked world: New roles and responsibilities. In C. Gibson (Ed.), Distance Learners in Higher Education (pp. 97-112). Madison, WI: Atwood Publishing.

Anderson, G. J., \& Walberg, H. J. (1974). Learning environments. In H. J. Walberg (Ed.), Evaluating educational performance: A sourcebook of methods, instruments and examples (pp. 81-98). Berkeley: McCutchan Publishing.

Ashburn, E., \& Floden, R. (2006). Meaningful learning using technology - What educators need to know and do. New York: Teachers College Press.

Berge, Z., \& Huang, Y. (2004). A model for sustainable student retention: A holistic perspective on the student dropout problem with special attention to e-learning. DEOSNEWS, 13(5).

Chang, V., \& Fisher, D. (2001, December 2-6). The validation and application of a new learning environment instrument to evaluate online learning in higher education. Paper presented at the Australian Association for Research in Education, Fremantle. Retrieved from: http://www.aare.edu.au/01pap/cha01098.htm 
Coates, H. (2006). Student engagement in campus-based and online education. London: Routledge.

Dabbagh, N., \& Banna-Ritland, B. (2005). Online learning-Concepts, strategies, and applications. Upper Saddle River, NJ: Pearson.

Dille, B., \& Mezack, M. (1991). Identifying predictors of high risk among community college telecourse students. The American Journal of Distance Education, 5(1), 24-35.

Fraser, B. J. (1998). Classroom environment instruments: Development, validity and applications. Learning Environments Research, 1, 7-33.

Herbert, M. (2006). Staying the Course: A study in online student satisfaction and retention. The Online Journal of Distance Learning Administration, 9(4). Retrieved from: http://www.westga.edu/ distance/ojdla/winter94/herbert94.htm

Inoue, Y. (2007). Technology and diversity in higher education. Hershey, PA: Information Science Publishing

Janusxewsky, A., \& Molenda, M. (2008). Educational technology - A definition with commentary. New York: Lawrence Erlbaum Associates.

Jonassen, D. H., Peck, K. L., \& Wilson, B. G. (1999). Learning with technology: A constructivist perspective. Upper Saddle River, NJ: Prentice Hall.

Jones, J. (2008). Issues and concerns of directors of postsecondary distance learning programs regarding online methods and technologies. The American Journal of Distance Education, 22(1), 46-56.

Klopfher, L. E. (1971). Evaluation of learning in science. In B. S. Bloom, J. T. Hastings, \& G. F. Madus (Eds.), Handbook of formative and summative evaluation of student learning. New York: McGrawHill.

Kurtz, G., Amichai-Humburger, Y., \& Kantor, J. (2009). Psychosocial well-being of Israeli students and attitudes toward Open and Distance Learning (ODL). The International Review of Research in Open and Distance Learning (IRRODL), 10(2). Retrieved from: http://www.irrodl.org/index.php/irrodl/issue/view/35

Palloff, R., \& Pratt, K. (2001). Lessons from the cyberspace classroom. San Francisco: Jossey Bass.

Swan, K. (2001). Virtual interactivity: Design factors affecting student satisfaction and perceived learning in asynchronous online courses. Distance Education, 22(2), 306-331.

Weinert, F. E. (1999). Concept of competence: A conceptual clarification. In D. S. Rychen \& L. H. Salganik (Eds.), Defining and selecting key competencies (pp. 45-65). Seattle: Hogrefe \& Huber.

\section{Biographies}

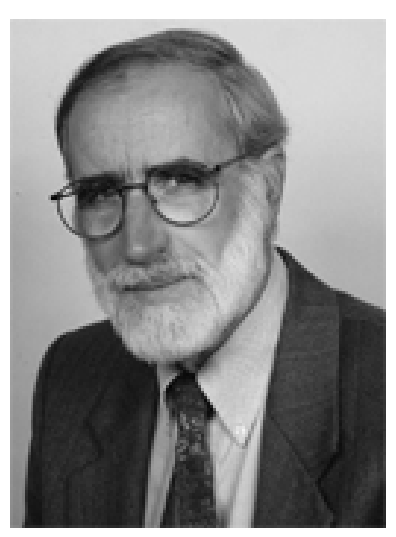

Michael F. Beaudoin, Ed.D. is Professor of Education at the University of New England in Portland, Maine, USA, where he was previously founding dean of a new college offering graduate, continuing, and distance education programs and courses. He is recognized for designing and directing innovative projects, including several successful distance education programs. He began his career in education as a Peace Corps Volunteer, and has held senior administrative positions at institutions in Maine, Massachusetts, Washington, DC, and Germany, various faculty appointments, and has been a visiting scholar in distance education at institutions in Germany, China, Ghana, Mexico, and Japan.

With over 75 publications and presentations, he has written extensively in the field of distance education and related areas, frequently presents at conferences and serves as an evaluator and consultant for distance education programs and courses. His book entitled 
"Reflections on Research, Faculty and Leadership in Distance Education" published in 2004 by the University of Oldenburg (GR), was winner of the Charles Wedemeyer Award for the book which made "A significant contribution to research in the field of distance education." His latest book, entitled "Perspectives on Higher Education in the Digital Age" published in 2006 by NOVA Science Publishers, Inc. includes chapters by leading practitioners and scholars in the field. He has present keynote addresses on distance education leadership at conferences and workshops in the US and abroad. He is on the editorial board of the Online Journal of Distance Learning Administration, Journal of Educators Online, and is the Book \& Media Reviews Editor for The American Journal of Distance Education. He is also a member of the International Board of Standards, Training, Performance and Instruction. Michael was awarded a Fulbright senior fellowship, and spent the 2007 spring term at University College of Education in Winneba, Ghana. He can be reached at mbeaudoin@une.edu

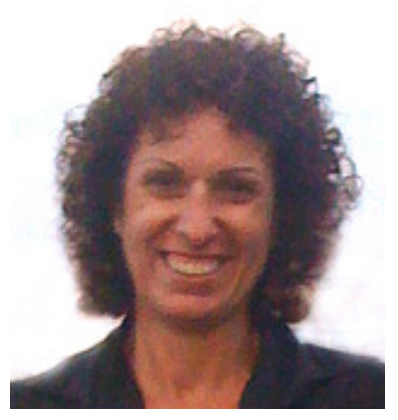

Gila Kurtz has been working at the Distance Education field for several years. Starting at 1995 as head of interactive television satellitebased unit at the Open University of Israel. (Interactive TV) at the Open University of Israel.

Currently, Dr. Kurtz is a professor in-charge of a Knowledge Technologies and Curriculum M.A. Program at the School of Education, The Center for Academic Studies in Israel. Before joining the Center for Academic Studies Dr. Kurtz served as a pedagogical director and later as a director of e-learning center at Bar-Ilan University.

Since 2001, Dr. Kurtz serves as an Adjunct Professor at UMUC Graduate School at the Master of Distance Education Program. She developed and teaches the courses: Technology in Distance Education and Synchronous and Asynchronous Learning Systems in Distance Education

She has a B.A. and M.A. from Tel-Aviv University and a Ph.D. from Bar-Ilan University. Her research activities are mainly related to the implementation of information technologies within the educational process.

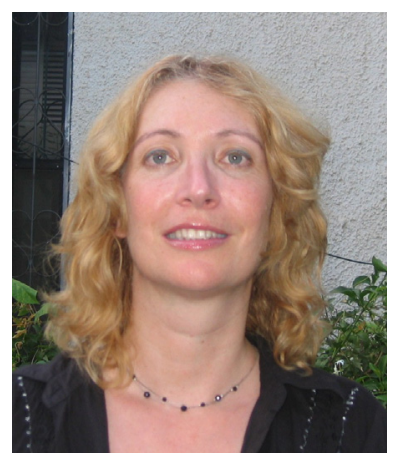

Sigal Eden is a fellow researcher and a member of the Chais Research Centre, the Open University of Israel, and a lecturer of Bar Ilan University, School of Education. She holds a B.A. in Education for Students with Hearing Impairment from Tel-Aviv University, an M.A. and Ph.D. in Educational Technologies from Bar-Ilan University. Her research interests and publications focus on various aspects of working with digital environments, especially the enhancement of cognitive and linguistic aspects among people with special needs. Personal site: http://www.openu.ac.il/research center_eng/Sigal_Eden_card E.html 